Gitation: Jiménez-Moreno, María J., Escalona-Maurice, M. J., RodríguezLaguna, R., Razo-Zarate, R., \& Acevedo-Sandoval, O. A. (2021). Conceptual proposal of the landscape as an environmental indicator for the spatial and temporal study of the territory. Agro Productividad https://doi. org/10.32854/agrop.v14i8.1782

Editor in Chief: Dr. Jorge Cadena Iñiguez

Received: February, 2021

Accepted: July, 2021.

Estimated publication date: September, 2021

This work is licensed under a Creative Commons Attribution-NonCommercial 4.0 International license.

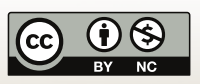

\section{Conceptual proposal of the landscape as an environmental indicator for the spatial and temporal study of the territory}

\author{
Jiménez-Moreno, María Josefa ${ }^{1}$; Escalona-Maurice, Miguel $\mathrm{J}^{2{ }^{*}}{ }^{*}$ Rodríguez-Laguna, Rodrigo ${ }^{3}$; \\ Razo-Zarate, Ramón ${ }^{3}$; Acevedo-Sandoval, Otilio. A. ${ }^{3}$ \\ 1 Instituto de Ciencias Básicas e Ingenierías, Universidad Autónoma del Estado de Hidalgo, México. \\ 2 Desarrollo Rural, Campus Montecillo, Colegio de Posgraduados, Carretera. Estado de México. \\ 3 Instituto de Ciencias Agropecuarias, Universidad Autónoma del Estado de Hidalgo, Tulancingo de Bravo, \\ Hidalgo, México. \\ * Corresponding author: mescalona@colpos.mx
}

\section{ABSTRACT}

Objective: To propose the landscape as an environmental indicator that spatially and temporally, describes, analyzes, and evaluates territory, by changing some natural, social, economic, and cultural components.

Approach: Different methodological concepts of the landscape and environmental indicators were reviewed, as well as their characteristics to describe and evaluate the environment.

Results: It was found that the landscape is a comprehensive analysis method for the study of the environment, by selecting the parameters that describe and represent each landscape, through shapes, size, colors, textures, shadows, patterns, situations, associated features, and structures arranged under a spatial and temporal order which, when perceived by humans, present a given form of organization or disorganization in the environment. Implications: The environmental indicator allows to analyze and evaluate the changes in space and time, with updated qualitative and quantitative research. These changes play an important role in building the perception of environmental problems through the landscape.

Conclusion: Landscape is an integral component that describes the biotic and abiotic elements of a given space. While, as an environmental indicator, it analyzes and evaluates changes in the composition and configuration of the environment, both spatially and temporally.

Keywords: ecosystem, natural resources, territory.

\section{INTRODUCTION}

Landscape is the image that humans perceive of their environment; as well, it is a natural resource able to be used (Rodríguez et al., 2013), which describes the integration of the spatial and temporal characteristics of the elements of nature (Allan et al., 2015; Jiménez et al., 2019). While an environmental indicator is the key instrument for planning natural resources that assesses the environmental, social, economic (He et al., 2011; Walz, 2015) and even cultural aspects, that determine the current condition of a particular ecosystem. 
The importance of the information obtained from the landscape is since any change in the composition and configuration of the environment may be used as an environmental indicator (Alphan, 2017), through qualitative (Delphi method, interviews, etc.) and quantitative (biodiversity models, regression, indices, etc.) techniques (Matovnikov and Matovnikova, 2016; Jiménez et al., 2019). Changes in landscapes are solid environmental indicators about mainly anthropogenic disturbances that should be monitored for decisionmaking. Thus, explaining the conditions and interactions of physical changes and social aspects of each element forming a place in a given time (Ginzarly et al., 2019). Therefore, a space-temporal environmental indicator studies, understands and evaluates the condition of the territory (Jiménez et al., 2019).

Based on the above, the objective was to propose the concept of landscape as an environmental indicator for the spatial and temporal study of territory. By the diversity of characteristics, it presents to describe, analyze, and evaluate the composition and configuration of an ecosystem. This is an analytical and comprehensively methodological process.

\section{Conceptual analysis of landscape and environmental indicator}

Landscape. It is a set of natural and cultural phenomena that describe the extension of a territory and provide information (Cruz-Medoza, 2018). They are complex systems, subject to rapid and extensive changes due to human activities affecting the environment (Alphan, 2017; Ginzarly et al., 2019).

Recent studies (He et al., 2011; Zhang et al., 2019) conceptualized landscape as the environmental factor linked to the subjective experience of analysis of a place that is characterized by positive and negative elements. Other authors (Walz, 2015; Cruz-Mendoza, 2018) consider the landscape as the integral and visual external expression of an ecosystem. This perception is produced on the environmental system, in a subjective and variable way through all senses of direct and indirect appreciation, which operate in the observer, for example: sight, hearing, smell, touch, among others. And, based on perceptual experience of the individual classification and valuation of each landscape is determined by relating a person with their space, which sets out the role of the landscape as an environmental indicator (Schindler et al., 2014; Ginzarly et al., 2019).

Landscape is a real, complex, and dynamic fact that exists in the earth's surface, the nature and characteristics are independent of the meaning attributed to it by human beings, through shapes, sizes, colors, textures, shadows, patterns, situations, associated features, and structures arranged under a spatial and temporal order. Which, perceived by a human present a given form of organization or disorganization in the environment (Matovnikov and Matovnikova, 2016; Cruz-Mendoza, 2018).

Consequently, human activity and the scenery of social life in each landscape is interpreted by the interactions between the biotic and abiotic elements of the natural environment (Alphan, 2017). Reason why landscapes are the consequence of natural and social evolution through time (Walz, 2015). 
Environmental indicator. It is a parameter that provides information, data, comparisons, and it evaluates situations of a place at a given time (Shul'kin et al., 2017), evidencing the impact of human beings on the biophysical and socioeconomic environment. For this reason, they are fundamental at the international, national, regional, and local levels, to describe and evaluate the consequences of human development (Rodríguez et al., 2013).

Environmental indicators provide useful information for planning and environmental assessment (Alphan, 2017; Gao et al., 2017; Luo et al., 2017), constitute a basic tool of information and monitoring of the processes occurring in the environment, in social and economic aspects. It explains the status and trends of natural resources in order to manage and formulate policies for programs aiming at the conservation and sustainable use of natural resources (Asumadu and Asantewaa, 2017), providing information in a simple and easy way to understand (Walz, 2015). In summary, they are useful for communicating scientific and technical information for the environmental management and to the general public (Schindler et al., 2014).

The use of environmental indicators has been of great relevance to science (Burkhard et al., 2015), because they allow to build the perception of the environmental problems, providing qualitative or quantitative information, as well as, evaluating decision alternatives and solutions (Schindler et al., 2014). These are fundamental instruments to generate and to analyze relevant information from environmental, social, economic, and even cultural aspects (Delgado et al., 2011; Rodríguez et al., 2013).

\section{The landscape on environmental study}

The landscape is a spatial unit of environmental analysis, which describes the structure forming a visual or surface image (He et al., 2011). It studies dynamic and functional aspects covering all the environmental components, and the influence of human beings (Ginzarly et al., 2019).

Landscape is a complex and deep concept which involves environmental, social, economic, and cultural aspects that determine the characteristics of a place. These must be taken to get to know the functioning of the territory (Rodríguez et al., 2013).

From a more general perspective, the landscape integrates configurations perceptible through sight and images. It reflects the state or condition of the nature it occupies, and the form of participation of each environmental component, determined by space and time of each process, which are key to the functioning of the environment (Gao et al., 2017; Jiménez et al., 2019). Within this context, the configuration of the landscape is complex and sensitive, subordinate to any change that affects its structure and environmental components (Walz, 2015).

The potential of the landscape depends on both the relationships between its components, as those relations with neighboring landscapes. Thus, it is conditioned not only by local characteristics, but also includes regional influence. This potential changes over time due to the levels of development of the society, and their needs (Delgado et al., 2011; Allan et al., 2015). 


\section{Importance of the environmental indicator on the composition and configuration of the territory}

Currently, human beings have made great modifications to their environment, that is, changes in the composition and configuration of nature, which is evident through an environmental indicator (Walz, 2015). This shows the situation of the environment in different analysis systems and determines the current diagnosis of the ecosystem (Bredemeier et al., 2015; Dyer et al., 2017).

Environmental indicators explain conditions and interactions with each element forming the place (space) at a given time (temporary) (Ginzarly et al., 2019; Jiménez et al., 2019). They expose those environmental problems caused by socioeconomic activities involving human beings for their development and growth (Asumadu and Asantewaa, 2017). They analyze and evaluate environmental conditions likely to improve through environmental management and the scope on the ecosystem (He et al., 2011; Gao et al., 2017). Those which can be described by different definitions, specifications, guidelines, statistics and classifying categories; they should be practical and realistic, as statistical, social, demographic and economic systems that allow us to observe changing trends, predictive situations, and they provide signs of possible future scenarios (Rodríguez et al., 2013; Walz, 2015).

\section{Analysis and approach of the landscape as environmental indicator}

The landscape as an environmental indicator describes, analyzes and evaluates environmental problems affecting ecosystems due to human intervention (Alpha, 2017). Conceptually, landscape is dynamic, because it analyzes the environment in a consistent relationship within a theoretical and practical context, to show a comprehensive environmental assessment from different perspectives (environmental, social, economic, and cultural) of each landscape (Rodriguez et al., 2013; Asumadu and Asantewaa, 2017).

A landscape represents the external condition of the environment in which some biotic and abiotic components are evaluated, on the use and extraction of natural resources. It also shows, the degree of social development and the quality of environmental management (Ginzarly et al., 2019). It considers limitations on the stability conditions of an ecosystem, based on a spatially and temporally related study of the landscape (Jiménez et al., 2019); those conditions are due to environmental and social characteristics (Delgado et al., 2011; Walz, 2015).

Any change in the configuration of landscape can be used as an environmental indicator (Jimenez et al., 2019), which describes (qualitatively) and generates quantitative information to analyze and assess the condition of that landscape.

The landscape as an environmental indicator aims to be an effective tool in the (spatial) study of the territory, in a conceptual and methodological way, because it involves (temporarily) those environmental, social, economic and cultural disturbances occurring at a specific moment (Alphan, 2017; Jiménez et al., 2019). An environmental indicator is one of the most important components of the landscape, because of its spatial, temporal and comprehensive aspects, integrated from different (environmental, social, economic and cultural) perspectives of evaluation. Such analysis must be planned and assessed, aiming to offer major contributions to knowledge, intending to explain 
different components of the environment for the benefit of nature and human beings (Gruz-Mendoza, 2018).

The aforementioned defines the landscape as an environmental indicator that describes, analyzes and evaluates ecosystems, and thus it can be used with applications on management and environmental analysis (Burkhard et al., 2015; Luo et al., 2017). It shows the ecological fragility and the degree of conservation, identifying the most sensitive elements of the environment, as well as the risks of breaking the environmental balance and moreover, the ecological behavior (Rodríguez et al., 2013).

Landscape as an environmental indicator is not a static and passive depiction, but images full of dynamic meanings, composed of biotic and abiotic components showing developments and imbalances, most of them caused by human activities on ecosystems (Gruz-Mendoza, 2018). Landscape explains the situation of the environmental components, and shows through scenarios perceived by people, complex images in which it is possible to detect the nature of the environmental components participating in the ecosystem (Ginzarly et al., 2019). Likewise, its comprehensive character allows those elements forming the landscape to appear not in a disaggregated manner but integrated into complex systems that bring us closer to the real understanding of nature (He et al., 2011).

For example, a landscape seen as an environmental indicator describes the climate, flora, fauna, soil types, as well as the consequences of human activities on the ecosystem and the magnitude of environmental impacts. It shows and evaluates the need for protection in the face of certain natural events caused by humans, which are dangerous for the very survival of the landscape, and which threaten the integrity of the ecosystem (Alphan, 2017; Jiménez et al., 2019).

The landscape is a fundamental component of the ecosystem and its character as a globalizing environmental indicator from an integral perspective, establishes direct contact between human beings and their environment in which he is immersed and of which he is a part (Ginzarly et al., 2019). In other words, it shows the consequences of human perception and assessments, becoming a useful instrument as an environmental indicator for environmental management (Rodríguez et al., 2013). In addition to this, an adequate understanding of the characteristics of the landscape shows the causes of environmental problems, and the consequences of the human impact on ecosystems (Alphan, 2017).

\section{GONGLUSIONS}

The landscape as an environmental indicator is an effective tool to describe, analyze and evaluate changes in the configuration of the territory. It provides analytical and methodological direction, spatially and temporally comprehensive to incorporate different perspectives of study (environmental, social, economic, and cultural), and it is essential for management and planning.

\section{REFERENGES}

Allan, E., P. Manning, F. Alt, J. Binkenstein, S. Blaser, N. Blüthgen, S. Böhm, F. Grassein, N. Hötzel, V. H. Klaus, T. Kleinebecker, E. K. Morris, Y. Oelmann, D. Prati, S. C. Renner, M. C. Riling, M. Schaefer, M. Schloter, B. Schmitt, I. Schöning, M. Schrumpf, E. Solly, E. Sorkau, J. Steckel, I. SteffenDewenter, B. Stempfhuber, M. Tschapka, C. N. Weiner, W. W. Weisser, M. Werner, C. Westphal, 
W. Wilcke.,Fischer, M. (2015). Land use intensification alters ecosystem multifunctionality via loss biodiversity and changes to functional composition. Ecol. Lett. 18 (8): 838-843. Doi: 10.1111/ele.12469

Alphan, H. (2017). Analysis of landscape changes as an indicator for environmental monitoring. Environ. Monit. and Assess. 189 (1): 24. Doi: 10.1007/s10661-016-5748-7

Asumadu, S. S., Asantewaa, O, P. (2017). The impact of energy, agriculture, macroeconomic and humaninduced indicators on environmental pollution: evidence from Ghana. Environ. Sci. and Pollut. Res. 24(7): 6622-6633. Doi: 10.1007/s11356-016-8321-6

Bredemeier, B., G. von Haaren, S. Rüter, M. Reich., Meise, T.(2015). Evaluating the nature conservation value of field habitats: A model approach for targeting agri-environmental measures and projecting their effects. Ecol. Modell. 295:113-122. Doi: 10.1016/j.ecolmodel.2014.08.010

Burkhard, B., B. Fath, S. E. Jørgensen., B., Li, L. (2015). Use of ecological indicators in models. Ecol. Model. 295: 1-4.Doi: 10.1016/j.ecolmodel.2014.10.016

Cruz-Mendoza, A. E. (2018). El trabajo de campo y la identificación de paisajes con potencial para el turismo en el volcán Nevado de Toluca, Estado de México. Invest. Geo. 95: 1-13. Doi:10.14350/rig.59639

Delgado P., J. J., J. D. Ruíz S., E. Navarro J., R. Cortes M., R. Remond N., E. Salinas C., J. M. Fernández L., P., Acevedo R. (2011). La degradación ambiental de los paisajes en las cuencas tributarias de la Ensenada de Sibarimar (Guanabo e Itabo, Cuba). Cuadernos Geográficos. 48: 161-188. https://www. redalyc.org/pdf/171/17121091006.pdf

Gao, J., P. Christensen., Kornov L. (2017). Indicators' role: How do they influence Strategic Environmental Assessment and Sustainable Planning The Chinese experience. Sci Total Environ. 592: 60-67. Doi: 10.1016/j.scitotenv.2017.02.211

Ginzarly, M., A. Pereira R., Teller, J. (2019). Mapping historic urban landscape values through social media.J. Cult. Herit. 36: 1-11. Doi: 10.1016/j.culher.2018.10.002

He, X., Y. Gao., J. Niu., Zhao, Y. 2011. Landscape Pattern Changes under the Impacts of Urbanization in the Yellow River Wetland taking Zhengzhou as an example. Procedia Environ. Sci. 10: 2165-2169. Doi: 10.1016/j.proenv.2011.09.339

Jiménez M., M. J., R. Rodríguez L., M. J. Escalona M., R. Razo Z., Acevedo, O. A S. (2019). Análisis de indicadores ambientales espacio-temporales de agua, suelo y vegetación. Rev. Mex. Cienc. Agrí. 10(7): 1641-1652. Doi: 10.29312/remexca.v10i7.1806

Luo, J., W. Huai, Gao, M. 2017. Indicators for environmental dispersion in a two-layer wetland flow with effect of wind. Ecol. Indic. 78: 421-436. Doi: 10.1016/j.ecolind.2017.03.027

Matovnikov, S., A., Matovnikova, N. G. (2016). Innovative Urban Planning Methods for the Urban Landscape Design in the Volgograd Agglomeration. Procedia Eng. 150: 1966-1971. Doi: 10.1016/j. proeng.2016.07.199

Rodríguez G., M. L., J. López B., Vela, G. C. (2013). Indicadores ambientales biofísicos a escala detallada para la planeación territorial en Milpa Alta, Gentro de México. Invest. Geog. 80: 21-35.

Schindler, S., H. von Wehrden, K. Poirazidis, W. M. Hochachka, T. Wrbka, Kati, V. (2014). Performance of methods to select landscape metrics for modelling species richness. Ecol. Model. 295: 107-112. Doi: 10.1016/j.ecolmodel.2014.05.012

Shul'kin, V. M., A. I. Kachur., Kozhenkova, S.I. (2017). Environmental Objectives and Indicators of the State of Marine and Coastal Zones in the Northwest Pacific Region. Geogr. Nat. Resour. 38: 52-59. Doi: $10.1134 / \mathrm{S} 1875372817010073$

Walz, U. 2015. Indicators to monitor the structural diversity of landscapes. Ecol. Model. 295: 88-106. Doi: 10.1016/j.ecolmodel.2014.07.011

Zhang, D., Q. Huang, C. He, D. Yin, Liu, Z. 2019. Planning urban landscape to maintain key ecosystem services in a rapidly urbanizing area: A scenario analysis in the Beijing-Tianjin-Hebei urban agglomeration, China. Ecol. Indic. 96: 559-571. Doi: 10.1016/j.ecolind.2018.09.030 